Gimself again. A pint of beer would make him appear intoxicated, and he remained deaf on one side. He was given some light work to do on the line, and was struck and killed by an engine. It was found that there had been an extensive fracture of the petrous portion of the temporal bone. A considerable part of the fracture had been smoothly and firmly united. In other parts there were intervals There was $n$ o appearance of any ca'lns having been thrown ont. The preparation is in the causeam of the $R$ syal College of Surgeons of England.

CASE 7 -A private patient had long suffered from some irritation in pssing urine, and had an instrument introduced. After this he passed a small calculus, and on one side of this there was an accurate mou'd of the opening 3 of the spermatic ducts It was placed in the museum of st. George's Hos oital.

CASE 8 - In Norfolk one day I met a clergyman riding on hurseba :k. During our conversation his horse suddenly became restive, and jum ped ahout a good deal. Very soon after this $\mathrm{g}$-ntleman told me that a $\mathrm{sm}$ ill stone bad jassed from the urethra In this case, as in the last, the aloulas $d$ ubthess came from the prostate gland.

Queensborough-terrace, $\mathrm{W}$.

\section{REFLEX EPILEPSY.}

BY WILFRED J. HARRTS, M B.CANTAB., M.R.C.P.LoND. JUNIOR MEDICLL TUTOR, ST. MIRY'S HOSPITAL; LATE SENIOR HOUSE PHYSICIAY, NATIONAL GOSPITAL FOR THE PARALYSED AND

EPILEPTIC, QUEEN-SQUARE.

EPILEPTIC fits associated refloxly with some cuuse such as irritation of a scar, a diseased eyeball, or disease of the masal mucous membrane, hava oscasionally been met with. That is, such cases have developed an epileptogenous zone, analogous to Brown-Séquard's guinea pigs rendered epileptic by hemisection of the spinal cord, and in some cases removal of the peripheral suurce of irritation has been followed by cessation of the fits Dc. Hughlings Jackson ${ }^{1}$ is of opinion that every patient subject to fits has an epileptogenous $\mathrm{z}$ )ne, that in every epileptic patient there is a "discharging lesion " somewhere in the brain, and that disturbance of the part of the periphery (cutaneous, visceral, \&3.) most especially represented in this discharging lesion may provoke. a fit. Sir W. Gowers ${ }^{2}$ on the other hand, states: "It is excessively rare for cutaneous irritation to excite a fit. Epileptogenic zones, analogous to those of Brown-Séquard's guineapigs are practically unkno wn." Two cases have hitherto been recorded of epileptic fit following a touch on the head-one by Dr. James Dansmure ${ }^{3}$ in 1874 , and one by Dr. Hughlings Jackson ${ }^{4}$ in 1887. Both these cases were in boys, and in each thera was partial hemiplegia, more marked after the attacks. In the older case there was slight right hemi. plegia, with temporary right-sided paralysis after the attacks. In Dr Jackson's case the weakness was left-sided. In both fits were prodncible during sleep, and also tonching any part of the head in eicher case, if the patient were maware that he was going to be touched, produced a sudden iall or fit lasting a few seconds. Dr. Dunsmure's case was watched for eignteen years, the falls becoming less frequent after the onset of severe epileptic fils, and improvement was marked during the administration of bromides, as in Dr. Jackson's patient In each case the attack began at the age of two and a half years, but the attacks, being so short in duration, momentary falls only, loss of consciousness daring them could only be surmised, though it was probable. Dhrough the kindness of Dr. Jackson I am enabled to give the details of another somewhat similar case which wa zader his care at the National Hospital for the Paralysed and Epileptic recently, though in this case there were never any uuilateral symptoms or hemiplegia, nor were any fits erer produced daring sleep.

A girl, aged fire and a half years, was admitted to the dational Hospital for the Paralysed and Epileptic on Nor. 10;h, 1896 She was a seren-months' chilu', the labour baring been natural, and no instruments used. The father

Transactions of the Mediral Society of London, vol. x., 1887. Manual of Diseases of the Nervous System, p. 742

:Edinburgh Medical Jourual, October, 1874; alsj quoted by $\mathrm{Dr}$ Hughliags dackson in ThE LaYceT, Feb. 2nd, 1895. 4 Loc. cit. was stated to have suffered from syphilis before his marriage. There were tbree otber younger children, all healthy, with no history of epilepsy in the family. The patient had not had chorea, rheumatism, or scarlet fever. When three years old she had a series of convulsions during one morning, but bad no further attacks until nine months previous to admission. One month before this attack she bad a fall, striking the back of ber head, and she was dazed for some time afterwards, though whether the fall was due to a fit could not be ascertained for certain. A month later she began to fall about especially in the morning, and at first always fell on the back of ber head, though later she always fell forwards. Her parents said that the fits were always slight and momentary; her eyes turned up and the face sometimes twitched and she suddenly fell down, of ten striking her head or biting her lip. She had these attacks sometimes once only, sometimes a dozen during the day. After she had suffered from them for between two and three months her mother noticed that the fits were induced by touching her on the head, as by putting the hand on her forebead, or when smoothing back her hair, or in putting no her hat. If she was expecting a touch, no fit followed. $\mathrm{O} a$ the day of ber admission the nurse, in going to her to take off her hat, accidentally touched her head, and the child immediately fell forwards, the father remarking that that was what frequently happened. The same day, when her left cheek was suddenly touched without her expecting it she in mediately fell forward, her eyes rolled up, and she foamed at the mouth, there being definite transient loss of consciousness, followed by crying. There was no weakness of any limb nor any sign of hemiplegia, and at no time were there any one-sided symptoms, as in both the previously recorded cases. The knee-jerks were normal and there was no allection of sensation. The eyes were normal and there was no affection of any cranial nerve. She was a quick, nervous child, but of uncertain temper, and her intelligence was probably below the normal. She was under observation in the hospital until March 7th of this year, and during her four months' stay she had numerous fits, only occasionally a day passing without one, though she was taking six grains of bromide of potassium three times daily during the whole time. All the fits except two were of nearly the same character, often occurring when she was sitting up in bed, and she would fall with some violence against the iron bedrail, giving herself a black eye, or sometimes biting her lower lip, and generally crying afterwards, even if not burt. The nurse noticed several fits induced by smoothing back her hair, and after her admission three sudden fits, momentary falls, followed by crying, were produced during the first month by suddenly tapping her on the head without her knowing the touch was coming. Touching her during her sleep never produced a fit or any sudden change of colour or alteration in respiration, as in the two cases referred to above. During the latter half of her stay in hospital no fit could be induced by sudden touches, the child seeming to become accustomed to the not infrequent testing, and the spontaneous fits were also slightly less numerous. Only two severe fits were seen, with general convulsion and cyanosis, one a fortnight after admission, and another ten weeks later. It is noteworthy that about this time the $r \in f l e x$ fits produced by sudden touches ceased; and in D c. Dunsmure's patient it was noticed that the sudden falls became less numerous when ordinary epileptic fits supervened.

Craven-terrace, $w$.

\section{A CASE OF CARBOLIC POISONING FROM THE APPLICATION OF A CARBOLIC COMPRESS TO THE SKIN.}

BY R. CLEMENT LUCAS, B.S. LOND., F.R.C.S. ENG., SURGEON TO, AND LECTURER ON ANATOMYY AT, GUY'S HOSPITAL.

IN The LANCET of June 1st, 1895, I published, in conjunction with my colleague, Mr. Lane, two cases of severe carbolic poisoning caused by the absorption of the poison through the skin when applied for the purpose of disinfecting the skin previously to operation. The principal symptoms were those of collapse and coma, lasting several hours; but, severe as the symptoms were, both recovered. Since that 
period it has been the custom in my wards to apply a 2 per cent. solution of lysol for the purpose of disinfecting the skin, and no untoward circumstance has followed the use of this agent. A constant change of dressers, however, occasionally causes an alteration in the routine of the wards, and this enables me to place on record another similar case to those already published, though less severe in character. My present house surgeon, Mr. R. P. Rowlands, happened to be my dresser at the time the other cases occurred, and so at once recognised the cause of the patient's illness, and to him I am indebted for very careful notes of the symptoms. It will be seen that this patient had been previously prepared with a lysol compress, but the operation had then to be postponed owing to the admission of an urgent case.

The patient. a girl, aged five years, was admitted into Lydia Ward, Gay's Hospital, on account of antero-external bending of the lower third of each tibia due to rickets. On July 15th, 1897, the left leg and foot were thoroughly washed and a lysol compress (2 per cent. solution) was applied in the morning, it being intended to perform an osteotomy in the afternoon, but owing to the admission of a case of strangulated hernia it became necessary to postpone the operation until the following day. At 11.45 1. M. on July 16 th the limb was again cleansed and a compress of carbolic lotion (5 per cent. solution) was applied on lint. This was applied over tne joot and the lower half of the leg. At 12.30 the child was crying lustily for her prohibited dinner, and she seemed to be quite well at that time. At 1.30 she was noticed to be lying back in her cot listless, pale, and sleepy. She gradually became worse, more drowsy and pale, until at 3 P.M. the house surgeon was called to see her. The child was then very pale, cold, clammy, and sweating profusely, especially about the head; the lips and tongue were of a peculiar dark colour, almost black, very different from ordinary cyanosis. The dark blood could also be seen through the pale skin, and added to the pallor of the latter a ghastly leaden undertint, which was very striking and led Mr. Rowlands correctly to interprat the cause of the symptoms. The patient was not absolutely comatose, as she could be roused by painful stimulation such as the use of a hypodermic syringe. She then threw her arms about for a moment before lapsing into her former limp and upconscious state. The limbs were flabby and could be dropped in any position, but were capable of movement under severe reffex irritation. The reflexes were all very dull and slow, that of the conjunctivæ was never absolutely lost, but very slow and feeble. The pupils were widely dilated and almost fixed. She passed her urine under her-a rare event for her-and she was sick several times. The pulse was feeble and running, almost imperceptible, and not to be counted at the wrist. The rate taken in the carotids was from 140 to 150 . The heart's impulse was feeble, diffused, and displaced outwards, balf an inch beyond the nipple line, and the cardiac sounds were muffled and tumbling in character. It was evident that there was considerable dilatation of the right side of the heart. The respirations were hurried and shallow, from 40 to 50 per minute. The temperature was $95^{\circ} \mathrm{F}$, in the rectum. The compress was immediately remored and the limb washed. Hot bottles were applied and the child was wrapped in warm blankets Ten minims of brandy were injected hypodermically at 3 P.M, and again fifteen minims at 4 P.M. About 4.30 P.M. the patient was better; the pulse was slower and stronger, and a pink flush had displaced the ghastly pallor of the cheeks. The skin was warmer. The pupils were now contracted. The patient was again sick several times, bringing up bilions-looking fluid. At 9 P.M. the temperature rose to $97^{\circ}$, and the coma gradually decreased, but she was not really sensible until the following morning. The skin became dry and rough towards morning, and the pupils dilated to normal. The temperature did not rise above normal at any time. She was not delirious nor did she try to get out of bed, but remained in a state of collapse. The urine passed in the night and early on the morning of the 17 th was of a peculiar smoky green colour, which darkened almost to black as it became ammoniacal. The child was again cheerful, but pale and weaker. The anæmia continued several days, but otherwise she appeared well.

The symptoms present in this case very closely resemble those present in the two cases published in June, 1895general appearance of shock or collapse, with cold sweating skin and actual diminution of normal temperatare. With this an exceedingly rapid pulse is found, imperceptible at the wrist, but counted elsewhere it was in one case 200, in a second case 150, and in the present instance from 140 to 150 per minute. Vomiting occurred at intervals, the vomit being of a pale, dusky blue appearance. Coma was more or less complete, and often there was stertorous breathing. The pupils in the present case were at first dilated, but afterwards contracted. The heart in the case now reported was found to be dilated and overdistended, so that its apex was felt external to the nipple Dark-coloured urine was passed after some hours. Convulsive twitchings were noticed in the other cases similar to what are seen in uræmia, and the urine was for a time suppressed. With a return of warmth the coma gradually subsides, but the patient remains for a time pale, weak, and drowsy.

Wimpole-street, $\mathbf{w}$

\section{Clinital âtrotes:}

\section{MEDICAL, SURGICAL, OBSTETRICAL, AND} THERAPEUTICAL.

\section{A CASE OF ENGLISH CHOLERA.}

\section{By R. G. Btyle, M.R.C.S. Eng.,}

SURGEON TO QUREN ADELATDE DISPENSARY.

ON Aug. 12th, at 11 A.M., I was called to see a girl, aged seventeen years, a paper sorter by trade. On examining her I found her to be in a state of extreme collapse; the face, body, and extremities were of a leaden hue. The tongue was clean, the eyes were sunken. There was no radial pulse. The temperature was $94^{\circ} \mathrm{F}$. The nails were livid and the hands were somewhat contracted. There was no. abdominal tenderness or distension, the patient only complained of slight pain in the bowels ; she was restless, and her countenance was peculiarly anxious-looking besides the. leaden hue. The history I obtained was as follows. The previous night she had had a supper of bread, cheese, and tomatoes, and subsequently, going out for a walk, she. bought and ate some fried potatoes at a fried fish shop. She went to bed at 11.30 P.M., and at 1 A.M. woke up with. romiting and had several loose evacuations. She was. removed from her own bed to that of her parents, and, they' state, slept quietly till 10 A.M. Shortly after this they noticed the colour of her face, and I was sent for. I administered injections of ether, and gave brandy and a diffusible stimulant mixture, ordered hot water buttles to the extremities, and a sinapism to the cardiac region. She was seen every hour till death occurred at 5.30 P.M.; she had only one stool after I saw her, which was described as frothy water. A necropsy was made twenty hours after death; rigor mortis was well developed. The brain substance was studded with ecchymoses, the sinuses were full of dark-coloured flaici blood. On opening the thorax the lungs were seen to be very collapsed, their lower edge corresponding with the fourth rib; they were congested at the kases; there were no ecchymoses. The pericardium did not contain any fluid; there were ecchymoses on it and many on the apex of the heart. The right ventricle and auricle contained clots of dark-coloured blood, typically "tarry" in character; there were ecchymoses in the right auricle ; the left ventricle contained a small ante-mortem clot. The gall-bladder was full of greenish bile. The liver was normal; the spleen and bott. kidneys were congested. The stomach contained about a pint of reddish-coloured fluid, mostly medicine and brandy and water. The whole of the intestines, from the duodenum to the rectum, were full of a creamy-coloured, semi-flocculent, inodorous fluid. The bladder was empty. Portions of the large and small intestines and the stomach have been submitted to bacteriological examination by Dr. Flein, the result being negative; no cholera vibrio was present, but the symptoms and post-mortem evidences were so suspicious that. I think I did wisely in notifying the case to the local anthorities and having disinfection promptly attended to.

Cambridge-road, N.E. 